\title{
EMBRYO-ENDOMETRIAL RELATIONSHIP IN THE MOUSE DURING ACTIVATION OF THE BLASTOCYST BY OESTRADIOL
}

\author{
S. BERGSTRÖM AND O. NILSSON \\ Reproduction Research Unit, Biomedical Center, \\ Box 571, S-751 23 Uppsala, Sweden
}

(Received 16th November 1974)

\begin{abstract}
Summary. Blastocysts that have been activated for implantation by an injection of oestrogen become separated from the uterine surface by a layer of secretion. By $8 \mathrm{hr}$ after the injection, the trophoblast cytoplasm contains several glycogen granules, groups of ribosomes, and mitochondria of a condensed type. These ultrastructural changes are signs of the increased metabolic activity exhibited by the trophoblast at activation. It is suggested that the uterine epithelium keeps the trophoblast inactive by delivering only a minimal nutritive medium and that the epithelium activates the trophoblast by making more nutrients, probably some carbohydrate, available as a consequence of an oestrogen-induced increase in the secretory activity.
\end{abstract}

The mouse blastocyst is tightly surrounded by uterine epithelium during the diapause of experimentally delayed implantation (Nilsson, 1974). Due to the close proximity between blastocyst and endometrium, the former carries a number of imprints and represents a malleable cast of the uterine crypt in which it is lodged (Bergström \& Nilsson, 1973). It has been noted by scanning electron microscopy (SEM) that during early oestradiol-induced implantation, i.e. at blastocyst activation (McLaren, 1973), the number of imprints is markedly reduced before another set and another type of imprints appear at blastocyst attachment (Bergström, 1972a).

The SEM findings suggest that a secretion breaks the close blastocystendometrial contact of delayed implantation before the appearance of that luminal closure which is associated with trophoblast invasion. To investigate these hypotheses, both scanning and transmission electron microscopy have been used to examine the blastocyst-endometrial relationship soon after the induction of implantation by oestrogen. The report is a sequel of a paper describing the corresponding relationship at delay of implantation, before the injection of oestrogen (Bergström \& Nilsson, 1973).

The animals used were virgin albino female mice of the NMRI strain weighing 20 to $25 \mathrm{~g}$. They were ovariectomized on Day 3 of pregnancy (Day 1 being the day on which a vaginal plug was found) and subsequently were given $1 \mathrm{mg}$ progesterone daily in order to obtain an experimental delay of im- 
plantation (Yoshinaga \& Adams, 1966). Ninety-seven blastocysts were recovered from thirty-six mice for SEM and eight implantation sites from three mice were collected for TEM. All mice were killed between Days 7 and 9, $8 \mathrm{hr}$ after a subcutaneous injection of $0 \cdot 1 \mu \mathrm{g}$ oestradiol- $17 \beta$.

Blastocysts for SEM were recovered from excised uteri of anaesthetized mice by flushing with fixative $(2.5 \%$ glutaraldehyde in Soerensen's phosphate buffer, $\mathrm{pH} 7 \cdot 4$ ). After postfixation in $1 \%$ osmium tetroxide in Soerensen's buffer, the blastocysts were washed three times in redistilled water, placed in small drops of redistilled water on foils, and rapidly frozen by immersion in iso-pentane, cooled by liquid nitrogen. Freeze-drying was carried out at the temperature of dry ice $\left(-79^{\circ} \mathrm{C}\right)$ before mounting and coating with carbon and gold-palladium as previously described (Bergström, 1973). The SEM observations were carried out on a JEOL JSM-U3, run at a voltage of $15 \mathrm{kV}$.

Implantation sites for TEM were obtained by intravascular perfusion of fixative through the abdominal aorta using the glutaraldehyde fixative mentioned previously. Pieces of uteri were then carefully cut, postfixed in the osmium fixative, and embedded in Epon. The specimens were cut for light microscopy to find the sites with a blastocyst and then trimmed and sectioned for electron microscopy. Observations were made in a Philips 300 TEM. The SEM studies demonstrated that $8 \mathrm{hr}$ after oestradiol, the trophoblast cells displayed swellings, and prominent intercellular borders (Pl. 1, Figs 1 to 2). Compared to the appearance at $0 \mathrm{hr}$ (Bergström, 1972b), the influence of the surrounding epithelium seemed to have diminished and few imprints on the blastocyst surface could be traced. At the three-cell junctions, distinct knot-like structures appeared. The microvillous lining was denser than at $0 \mathrm{hr}$. In the majority of the specimens examined, the polarity of the blastocyst could be judged by a more marked convexity of the abembryonic cells than of the embryonic ones.

The TEM studies showed that the trophoblast was separated from the luminal membrane of the endometrium by a distance of about 0.5 to $2 \mu \mathrm{m}$ (Pl. 2, Fig. 3). The trophoblast possessed several microvilli. Compared to the appearance at $0 \mathrm{hr}$, several changes had occurred in the cytoplasm of the trophoblast. The ribosomes were arranged in groups instead of being scattered, the granular endoplasmic reticulum was more developed, and several glycogen granules had appeared. Further, the mitochondria were no longer of the vesicular type, present at $0 \mathrm{hr}$ (Pl. 2, Fig. 4), but of a condensed type with wide intracristae compartments (Pl. 2, Fig. 5).

The results demonstrate that when implantation is initiated by an injection of oestrogen, the mucosal grasp around the blastocyst loosens. This fact was suggested by SEM which showed that the imprints on the blastocyst surface disappeared (Bergström, 1972a) and was verified by the present TEM results. It seems possible that this change was caused by a luminal secretion.

Fig. 1. Activated mouse blastocyst, $8 \mathrm{hr}$ after the initiation of implantation. The blastocyst is expanded with bulging trophoblast cells. The abembryonic pole lies to the left. $\times 1000$. Fig. 2. Trophoblast cells of an activated mouse blastocyst. Several microvilli are observed. The intercellular borders appear as ridges at the blastocyst surface. $\times 4000$. 
PL.STH: 1

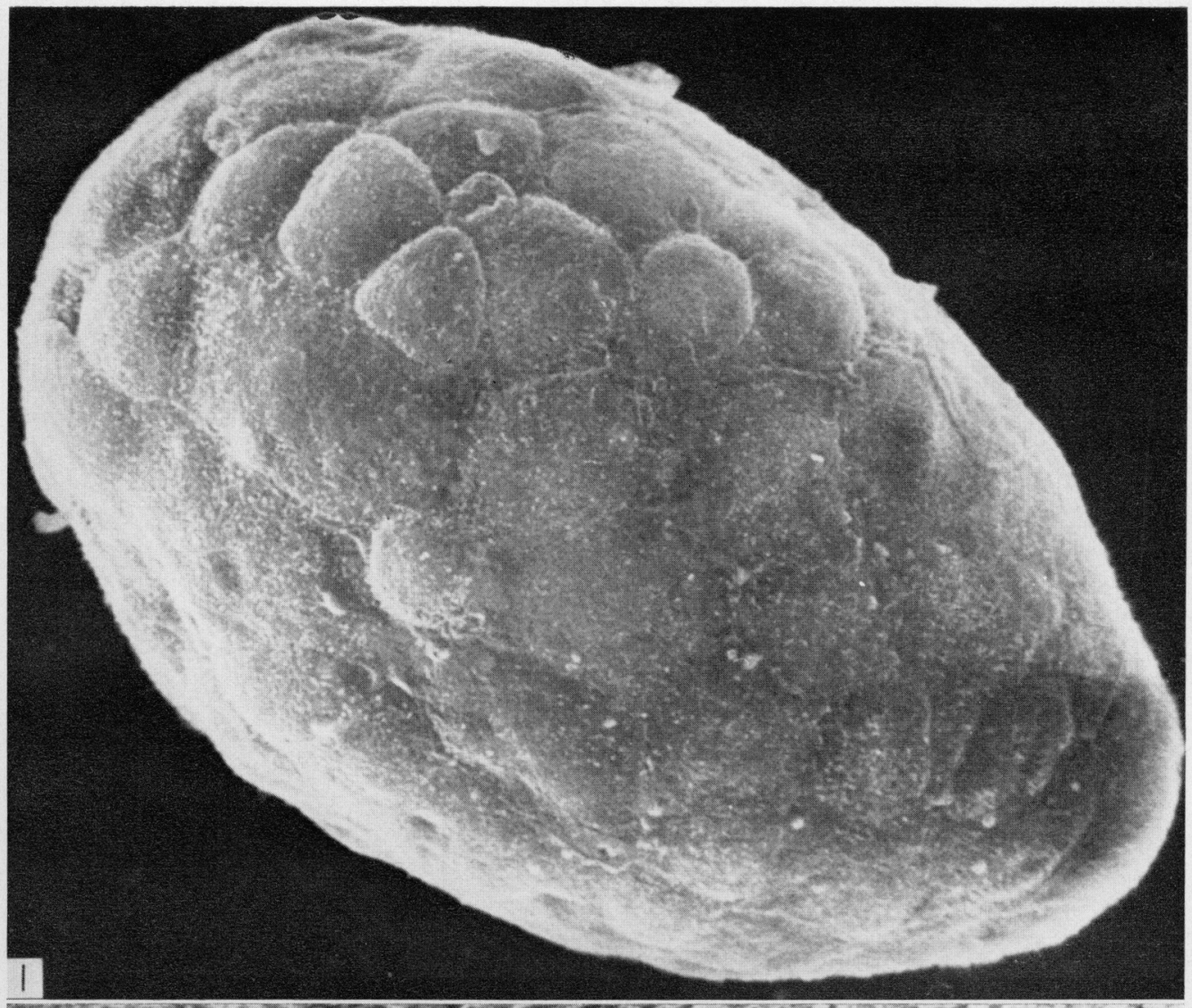

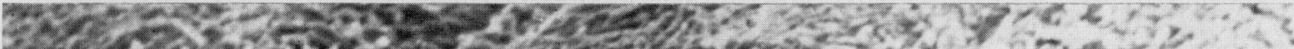

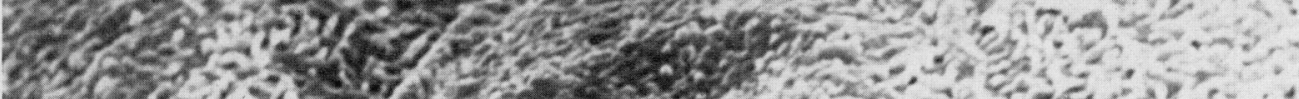

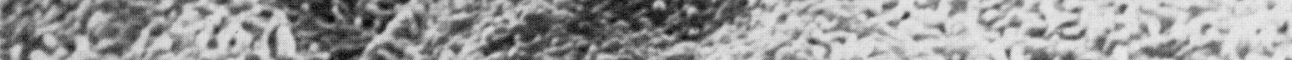

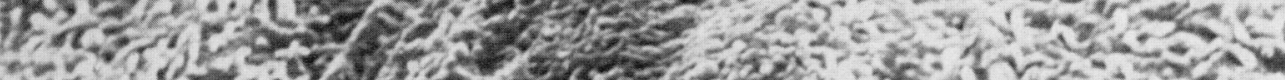

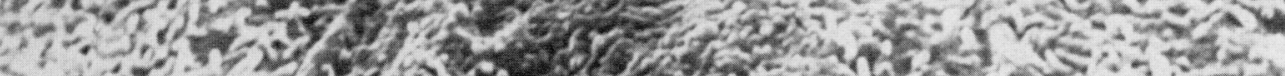

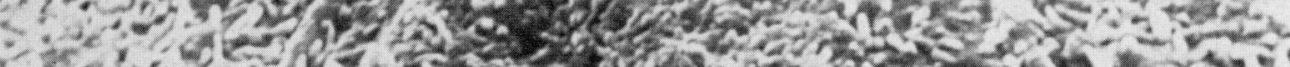
x.

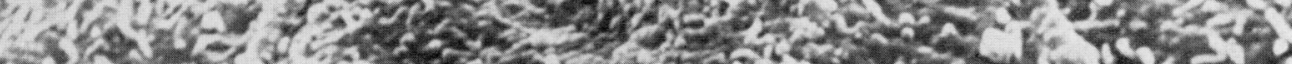

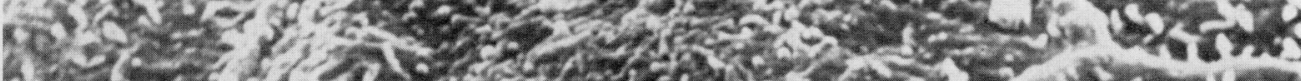

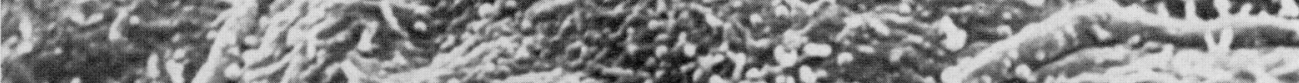

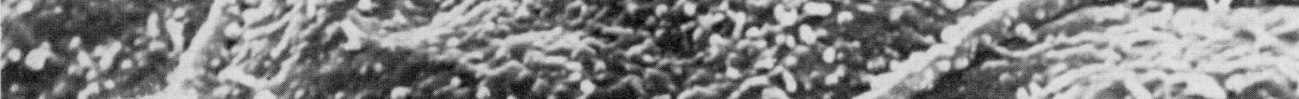

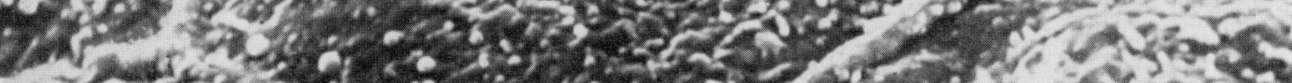

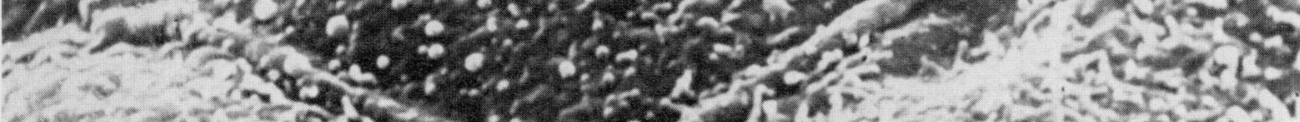

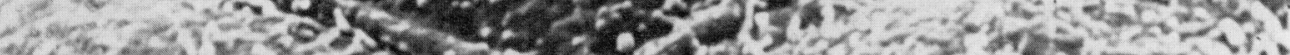

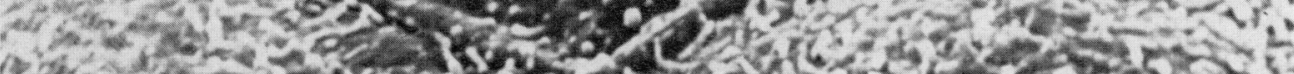

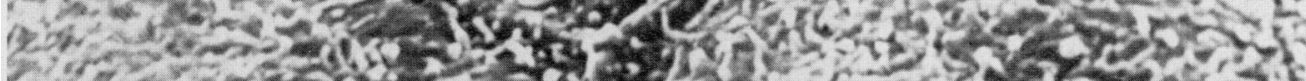

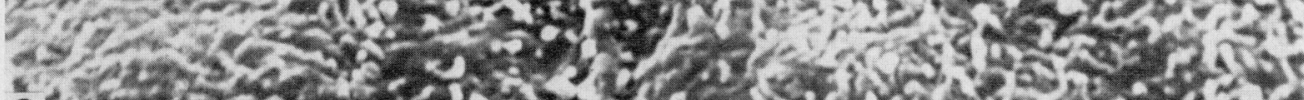
2. 
PLATE 2

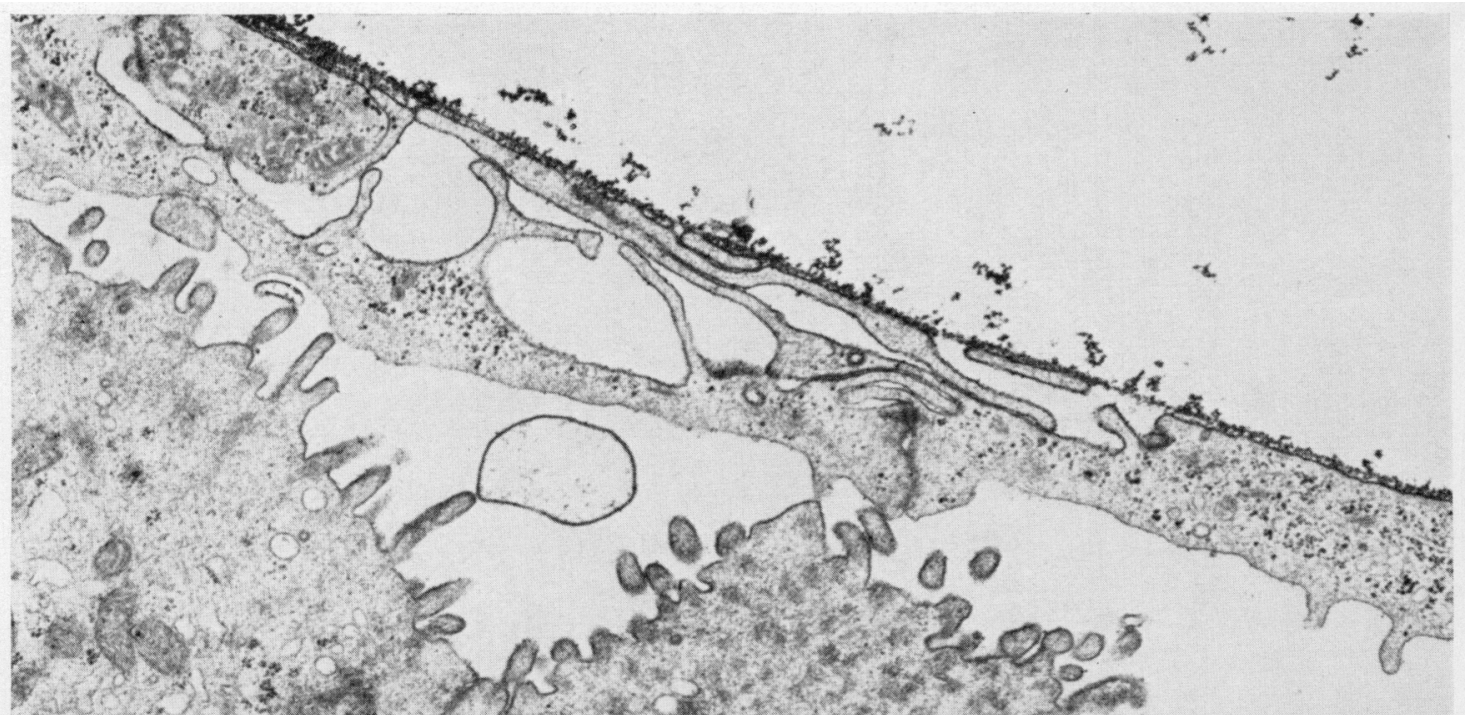

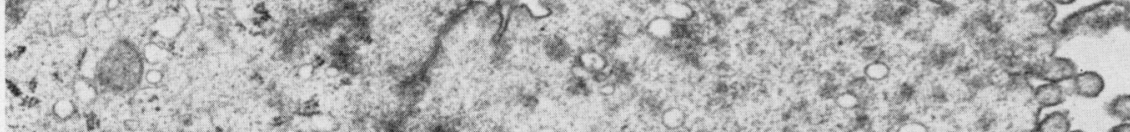

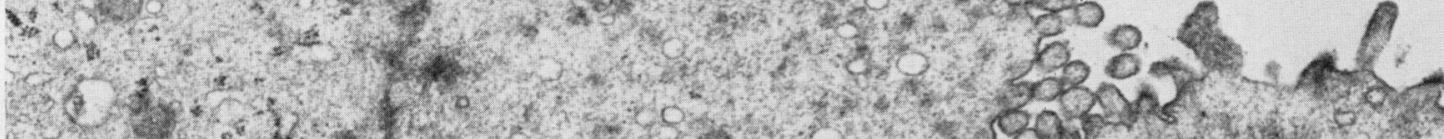

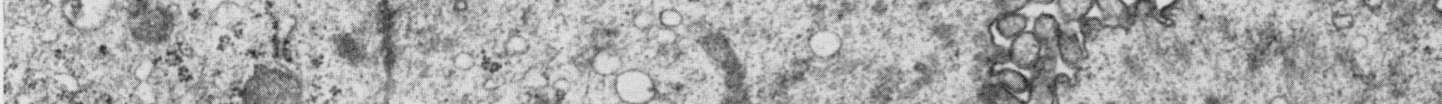

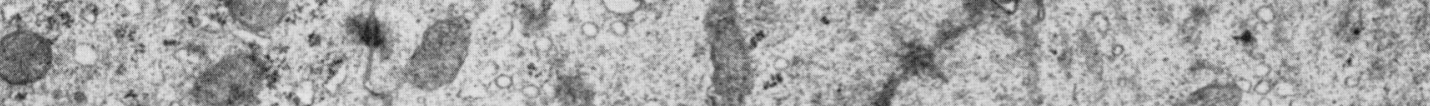

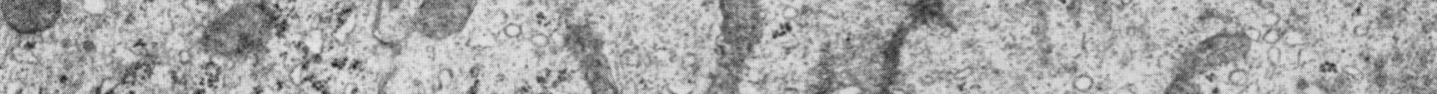

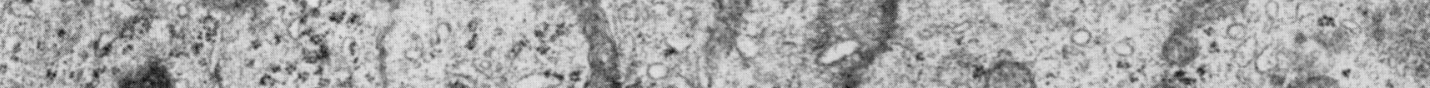

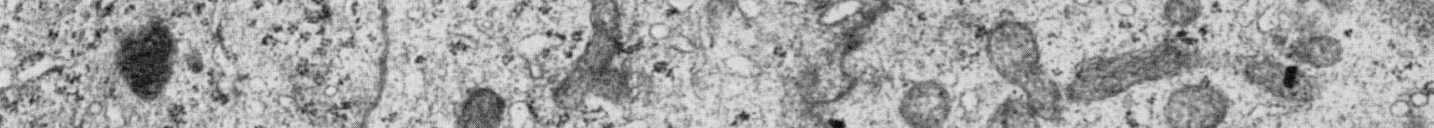

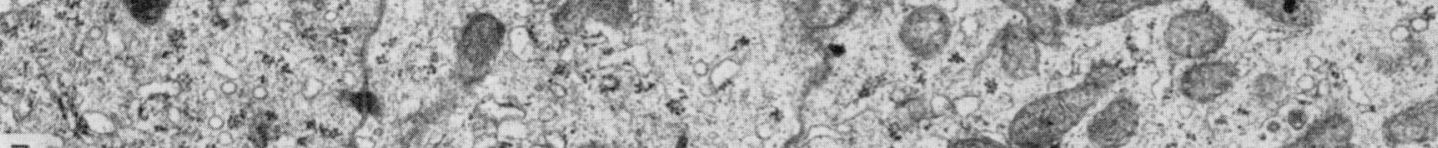

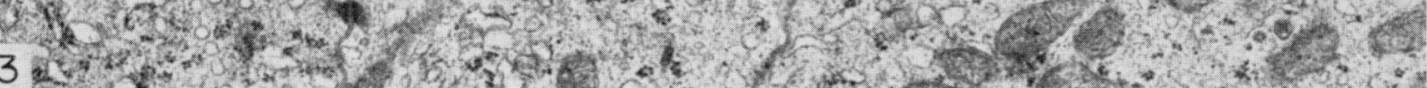
Q

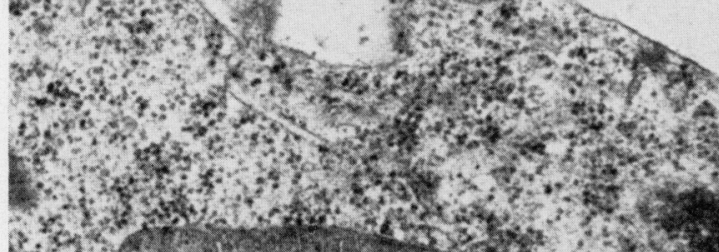

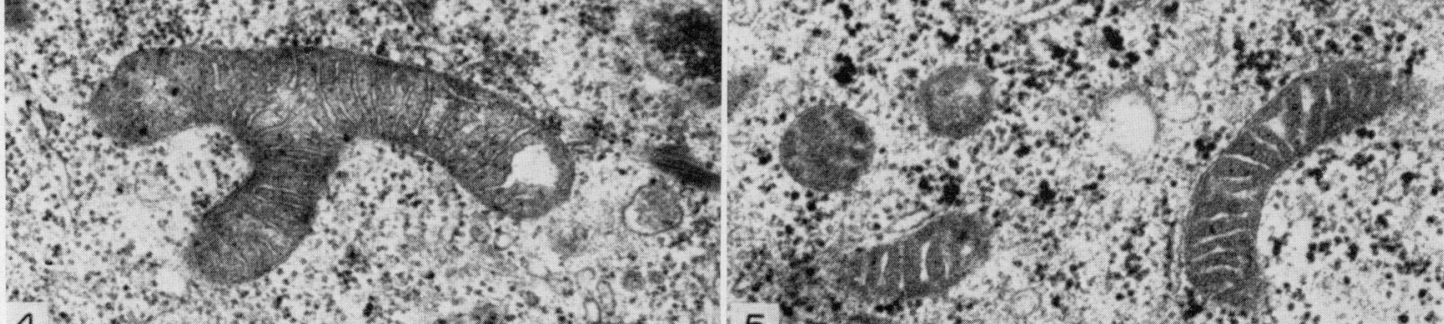

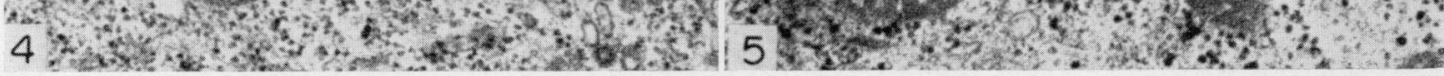


The ultrastructure of the activated trophoblast indicates that the conformation of the mitochondria has been changed and that glycogen has appeared. Furthermore, the protein synthesizing apparatus is now better developed as indicated by the increase in proportion of polysomes to monosomes (Black \& Webster, 1973). The ultrastructure of the mitochondria transforms to a type which may be associated with induced oxidative phosphorylation (Hackenbrock, Rehn, Weinbach \& Lamasters, 1971), or with binding or translocation of ADP (Weber, 1972). The trophoblast has thus attained a state of high metabolic activity. It needs oxygen, and may take up carbohydrates to produce the glycogen granules as an energy source (Ozias \& Weitlauf, 1971). These and other structural signs (for references, see McReynolds \& Hadek, 1972) of an increased metabolic activity of the trophoblast correspond with the various biochemical and functional changes observed (for references, see McLaren, 1973).

A trigger of the blastocyst activation might be some carbohydrate of the uterine secretion. This possibility is strengthened by the findings that cultured mouse blastocysts utilize glucose (Fridhandler, Wastila \& Palmer, 1967; Ozias \& Stern, 1973) and that their outgrowth is delayed when glucose is omitted in the medium (G. Naeslund, unpublished work). This hypothesis is further supported by the observation that the glucose content of the rat uterus is highest on Day 4 of pregnancy, the day when the blastocyst activation should occur (Greenstreet \& Fotherby, 1973). The activation of the roe-deer blastocyst also seems to be initiated by the appearance of hexose in the uterine secretion (Aitken, Burton, Hawkins, Kerr-Wilson, Short \& Steven, 1973).

The authors acknowledge their indebtedness for the technical assistance of Mrs Marianne Ljungkvist and Miss Barbro Pettersson, and the financial support of the Swedish Medical Research Council (Grant No. 12X-70).

\section{REFERENCES}

Atrken, R. R., Burton, J., Hawkins, J., KerR-Wilson, R., Short, R. V. \& Steven, D. H. (1973) Histological and ultrastructural changes in the blastocyst and reproductive tract of the roe deer, Capreolus capreolus, during delayed implantation. 7. Reprod. Fert. 34, 481-493.

Bergström, S. (1972a) Scanning electron microscopy of ovoimplantation. Arch. Gynäk. 212, $285-307$.

Bergström, S. (1972b) Delay of blastocyst implantation in the mouse by ovariectomy or lactation. A SEM study. Fert. Steril. 23, 548-561.

Bergström, S. (1973) Preparation of ova for scanning electron microscopy. Uppsala J. med. Sci. 78, 1-11. Bergström, S. \& Nilsson, O. (1973) Various types of embryo-endometrial contacts during delay of implantation in the mouse. 7. Reprod. Fert. 32, 531-533.

Black, O., JR \& Webster, P. D. (1973) Protein synthesis in pancreas of fasted pigeons. 7. Cell Biol. $57,1-8$.

\section{EXPLANATION OF PLATE 2}

Fic. 3. Implantation site in a mouse, $8 \mathrm{hr}$ after the initiation of implantation. The trophoblast cells are separated from the epithelium by a space of varying thickness. An intercellular junction between two trophoblast cells is shown. The junction is winding with large intercellular spaces and a protruding portion at its surface. $\times 18,000$.

Fio. 4. Trophoblast mitochondria from an inactive (delayed) mouse blastocyst. $\times 26,000$. Fic. 5. Mitochondria from an activated mouse blastocyst. The mitochondria are dense with wide intracristae compartments. $\times 26,000$. 
Fridhandler, L., Wastila, W. B. \& Palmer, W. M. (1967) The role of glucose in metabolism of the developing mammalian preimplantation conceptus. Fert. Steril. 18, 819-830.

Greenstreet, R. A. \& Fotherby, K. (1973) Garbohydrate metabolism in the rat uterus during early pregnancy. Steroids Lipids Res. 4, 48-64.

Hackenbrock, G. R., Rehn, T. G., Weinbach, E. C. \& Lamasters, J. J. (1971) Oxidative phosphorylation and ultrastructural transformation in mitochondria in the intact ascites tumor cell. 7. Cell Biol. 51, 123-137.

MaLaren, A. (1973) Blastocyst activation. In The Regulation of Mammalian Reproduction, pp. 321-328. Eds. S. J. Segal, R. Crozier, P. A. Corfman and P. G. Condliffe. Charles C. Thomas, Springfield, Illinois.

MaReynolds, H. D. \& HAdek, R. (1972) A comparison of the fine structure of late mouse blastocysts developed in vivo and in vitro. 7 . exp. Zool. 182, 95-117.

Nilsson, O. (1974) The morphology of blastocyst implantation. 7. Reprod. Fert. 39, 187-194.

Ozias, C. B. \& Stern, S. (1973) Glycogen levels of preimplantation mouse embryos developing in vitro. Biol. Reprod. 8, 467-472.

Ozias, G. B. \& Weitlauf, H. (1971) Hormonal influences on the glycogen content of normal and delayed implanting mouse blastocysts. F. exp. Zool. 177, 147-152.

WEBER, N. E. (1972) Ultrastructural studies of beef heart mitochondria. III. The inequality of gross morphological change and oxidative phosphorylation. 7. Cell Biol. 55, 457-470.

Yoshinaga, K. \& Adams, C. E. (1966) Delayed implantation in the spayed, progesterone treated adult mouse. 7. Reprod. Fert. 12, 593-595. 